EPJ Web of Conferences 106, 02006 (2016)

DOI: $10.1051 /$ epjconf/201610602006

(C) Owned by the authors, published by EDP Sciences, 2016

\title{
Uncertainties in the Fluence Determination in the Surveillance Samples of VVER-440
}

\author{
Joerg Konheiser ${ }^{1, \mathrm{a}}$, Alexander Grahn ${ }^{1}$, Pavel Borodkin ${ }^{2}$, and Gennady Borodkin ${ }^{2}$ \\ ${ }^{1}$ Helmholtz Zentrum Dresden-Rossendorf e.V., PF 510119, 01314 Dresden, Germany \\ ${ }^{2}$ SEC NRS, Malaya Krasnoselskaya ul, 2/8 bld.5, 107140 Moscow, Russia
}

\begin{abstract}
The reactor pressure vessel (RPV) represents one of the most important safety components in a nuclear power plant. Therefore, surveillance specimen (SS) programs for the RPV material exist to deliver a reliable assessment of RPV residual lifetime. This report will present neutron fluence calculations for SS. These calculations were carried out by the codes TRAMO [1] and DORT [2]. This study was accompanied by ex-vessel neutron dosimetry experiments at Kola NPP. The main neutron activation monitoring reactions were ${ }^{54} \mathrm{Fe}(\mathrm{n}, \mathrm{p}){ }^{54} \mathrm{Mn}$ and ${ }^{58} \mathrm{Ni}(\mathrm{n}, \mathrm{p}){ }^{58} \mathrm{Co}$. Good agreement was found between the deterministic and stochastic calculation results and between the calculations and the ex-vessel measurements. The different influences on the monitors were studied. In order to exclude the possible healing effects of the samples due to excessive temperatures, the heat release in the surveillance specimens was determined based on the calculated gamma fluences. Under comparatively realistic conditions, the heat increased by $6 \mathrm{~K}$.
\end{abstract}

\section{Introduction}

Reactor pressure vessels (RPV) are non-restorable equipment and their lifetime may restrict the nuclear power plant-life as a whole. Surveillance specimen (SS) programs for RPV materials are among the most important measures for in-service inspection programs necessary for realistic and reliable assessment of the RPV residual lifetime. In contrast to Western European reactor types, no surveillance specimens were provided in the Voda Voda Energo Reactors (VVER) in the basic project planning. Only the Finland reactors were equipped with surveillance specimens. In investigations of these specimens a more significant embrittlement of the material was found than it was expected [3]. This condition was a result of the chemical composition of the steel and its compact design in very high neutron fluxes.

The results from the Finnish samples motivated the provision of corresponding equipment for the irradiation of samples in VVER-440/213 reactors, and the obligation of surveillance specimen programs as part of the reactor design.

Guiding channels were welded to the outer wall of the shaft for the storage of the specimens during irradiation. Figure 1 shows a horizontal and vertical cross section of the channels. The specimens are in pressure-resistant austenitic steel containers, which are connected as a chain (see Fig. 1, right). Thus, it is possible to irradiate up to 20 containers per chain in the range of the reactor core. Six tensile or

\footnotetext{
${ }^{a}$ Corresponding author: j.konheiser@hzdr.de
}

This is an Open Access article distributed under the terms of the Creative Commons Attribution License 2.0, which permits unrestricted use, distribution, and reproduction in any medium, provided the original work is properly cited. 

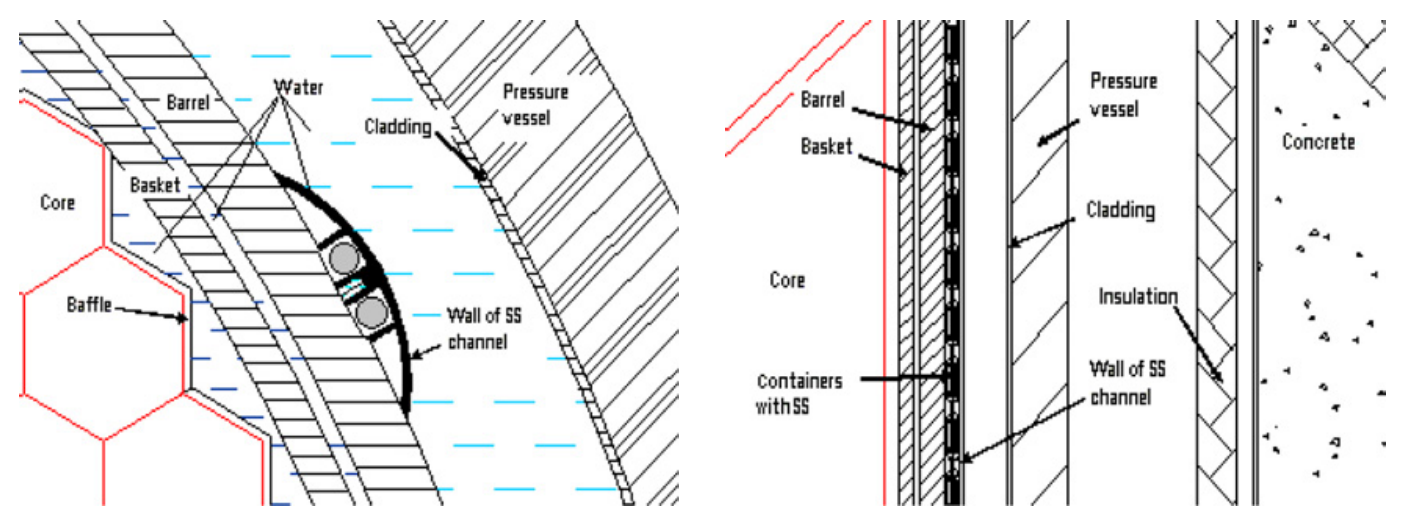

Figure 1. Horizontal and vertical sectional views of SS containers in the channels on the barrel.

two Charpy specimens can be found in each container. In addition, some of them contain temperature or neutron fluence monitors. A research program was started in Russia in parallel.

One part of the research program is the reactor dosimetry. Neutron and gamma fluences are calculated here both in the material specimens and in the RPV. The aim of this research is to determine the so-called "lead factor" of the specimens. The accelerated increase of neutron fluences in the specimens compared to the RPV describes the lead factor. Moreover, the calculations show possible differences in the neutron spectra. This could have effects on the embrittlement behavior of the specimens.

The calculation of neutron fluxes in the specimens were carried out both with the Monte Carlo code TRAMO [1] and with the deterministic code DORT [2]. TRAMO was used to calculate group fluxes for volumes and surfaces with the given source distribution. The program is optimized for the calculation of neutron and gamma fluences in the region of the reactor pressure vessel and its surroundings. The code was developed in Rossendorf. Russian colleagues carried out corresponding calculations with the international deterministic SN code DORT using the synthesis method.

The effects of the different possible positions of surveillance specimens to the reactor core were also examined because of the lack of knowledge of the exact position and orientation of the sample in the channel. The calculations were performed with a high spatial resolution so that at least one value was determined for each specimen within the container.

Russian colleagues validated the calculated results. The experiment consisted of fluence monitors which had been installed on the outside of the RPV. The monitors were irradiated in two horizontal levels and a vertical line. They were irradiated within one cycle at Kola NPP 3.

\section{Calculations}

\subsection{TRAMO}

The geometry has been developed largely based on data from a model provided by Russian colleagues. This model consists partly of two two-dimensional geometric models, and it was prepared per the licensed regulations of the SEC NRS. The RZ model was used for the TRAMO calculations. In this model, the regions above and below the core are modelled as several homogeneous discs. The discs differ in material composition. This design improves the comparability of results between TRAMO and DORT. In contrast, the geometry has been accurately described in the XY plane. In the channel area, the SS geometry is represented by polygons. Figure 2 shows a model of the channel region. It can be assumed that this will have practically no effect on the results because this model is very realistic. 


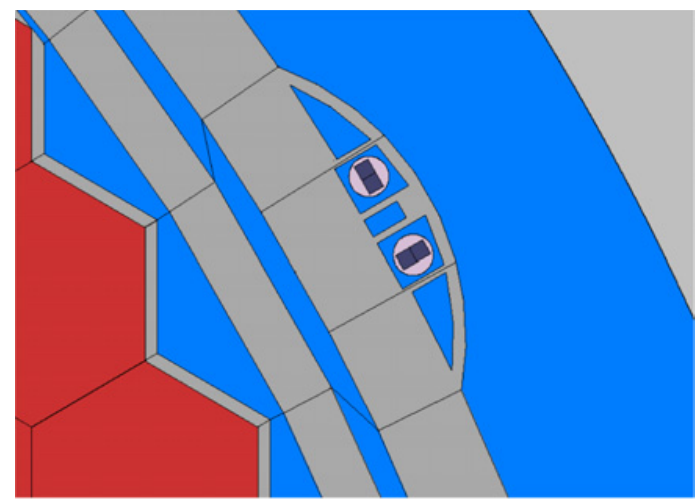

Figure 2. Modeling of the channel for the SS within the TRAMO calculations.

The nuclear data library used for the neutrons, including gamma production was ENDF/B-VII.0 [4] and PHOTX [5] for gamma transport. The energy structure of the neutron was SAND-IIA (640 energy groups of $20.0 \mathrm{MeV}$ to $0.0001 \mathrm{eV}$ ) and for the gammas CSEWG (94 energy groups from $20 \mathrm{MeV}$ to $10 \mathrm{keV}$ ). Temperature-dependent F-factors [6] were used to account for the influence of the resonance self-shielding of isotopes in the macroscopic cross sections of the material compositions. The dependence of the scattering angle of the transfer cross sections between the groups was developed as a P5 Legendre's polynomial for inelastic scattering. In contrast, equiprobable angle intervals were used for the elastic scattering and the scattering in the thermal energy region. In addition, $\mathrm{S}(\alpha, \beta)$ factors were used for some isotopes in the thermal energy region.

Russian colleagues provided the compositions of the materials. The change in material compositions caused by burn-up during a reactor cycle was ignored because of the small influence on transport. Separate parameter sets on the weight window were generated for the optimal calculation of the fluences in the horizontal and vertical monitors. Using these techniques, the statistical errors of the TRAMO results were below $1 \%$ in the majority of cases.

Assuming that the transport characteristics change only marginally or not at all, time-integrated sources can be used for the calculation of the fluence. SEC NRS provides the necessary data based on neutron physics calculations. The neutron source distribution contained 34 outer fuel assemblies. This is common because is generally known that the part of the sources of inner fuel assemblies at the flux in the RPV is very small (here $<1 \%$ ). Each fuel assembly was divided into 42 height layers. In addition, a pin-by-pin source distribution was considered for each fuel assembly. The determination of the activities of the monitor was carried out with the help of an "effective" source. This method already takes into account the decay of activity of the nuclide monitor during the source irradiation.

The source distribution of the prompt fission gammas was assumed to be equal to the neutron distribution. The total source of the gammas is the product from the neutron source and the ratio of the average number of prompt fission gammas (7.17) to the average number of fission neutrons (2.47). The delayed gammas were not considered because they would necessitate special burn-up calculations. Previous ORIGEN calculations [7] show that the number of gammas from the fission products is similar to the prompt fission gammas, but their energy spectrum is somewhat softer.

\subsection{DORT}

The three-dimensional (3D) synthesis method based on the discrete ordinates code DORT coupled with the BUGLE-96T library [8] (47 neutron/20 gamma groups) was used to calculate neutron fluence rate on the RPV, taking upscattering in the thermal region into account. In application to the VVER type 


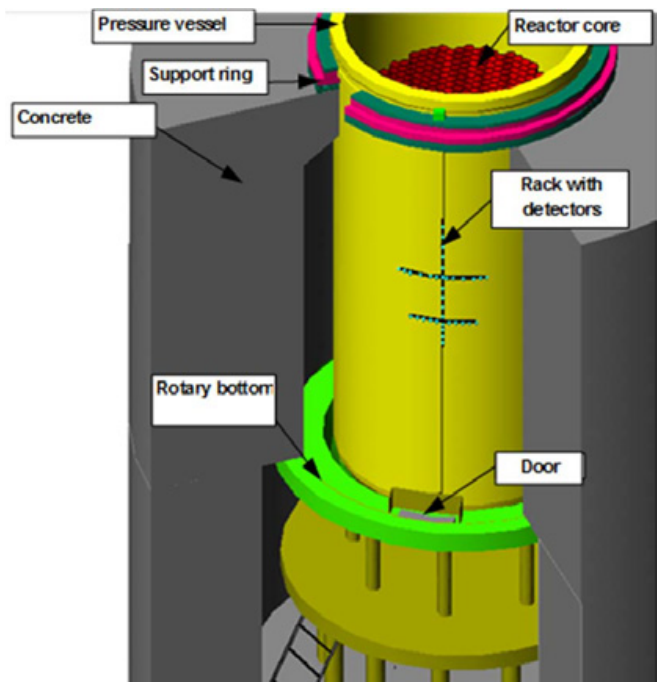

Figure 3. Scheme of detector set positions in ex-vessel cavity of Unit 3 of NPP Kola.

reactor, DORT calculations are performed in two-dimensional $(r, \theta)-,(r, \mathrm{z})$ - and $(r-)$ geometries. The $3 \mathrm{D}$ synthesized fluence rate in the neutron group $\mathrm{g}, \varphi_{g}(r, \theta, z)$ is expressed by the following modified relation [3]:

$$
\varphi_{g}(r, \theta, z)=\varphi_{g}(r, \theta) \frac{\varphi_{g}(r, z)}{\varphi_{g}(r, \theta=\text { constant })}
$$

where:

$\varphi_{g}(r, \theta), \varphi_{g}(r, z)$ and $\varphi_{g}(r, \theta=$ constant $)$ are $2 \mathrm{D}$ fluence rate distributions. Fluence rate $\varphi_{g}(r, \theta=$ constant $)$ is calculated using the same $2 \mathrm{D}(r, \theta)$ space grid, as for the calculation of $\varphi_{g}(r, \theta)$, but for a one-dimension cylindrical r-model. As remarked in [3], the advantage of this procedure is a reduction in non-physical $\theta$ oscillations.

The standard model from SEC NRS was used. The basic $(r, \theta)$ calculations were performed for 60-degree sector. For neutron source modelling in the 60-degree sector the 3D total neutron release distribution was used. Two peripheral assembly rows were modelled taking pin-wise source distributions into account. As in the TRAMO calculations, the material contents of $(r, z)$ layers above and below core were homogenized. In contrast, boric acid content in the coolant was taken into account in the DORT calculations. $\mathrm{P}_{3} \mathrm{~S}_{12}$ approximation was chosen as optimal for RPV fluence rate calculation.

\section{Monitor Experiment}

\subsection{Measurement}

Russian colleagues carried out the irradiation experiment at Kola NPP's Unit 3 reactor. This unit has been in operation since 1982, and will likely be decommissioned in 2026. Figure 3 shows the reactor used for the experiment. The fluence monitors were fixed by means of a rack to the outside of the RPV. The monitors have been irradiated on two horizontal planes and a vertical line. The levels of the planes were at $27.5 \mathrm{~cm}$ and $97.5 \mathrm{~cm}$ above the core bottom. Thirteen monitors were at the $97.5 \mathrm{~cm}$ level and eleven at the $27.5 \mathrm{~cm}$ level. This arrangement meant that the monitors were irradiated in the maximum horizontal flux and in the region of the critical weld. In the vertical direction, the monitors were in the 

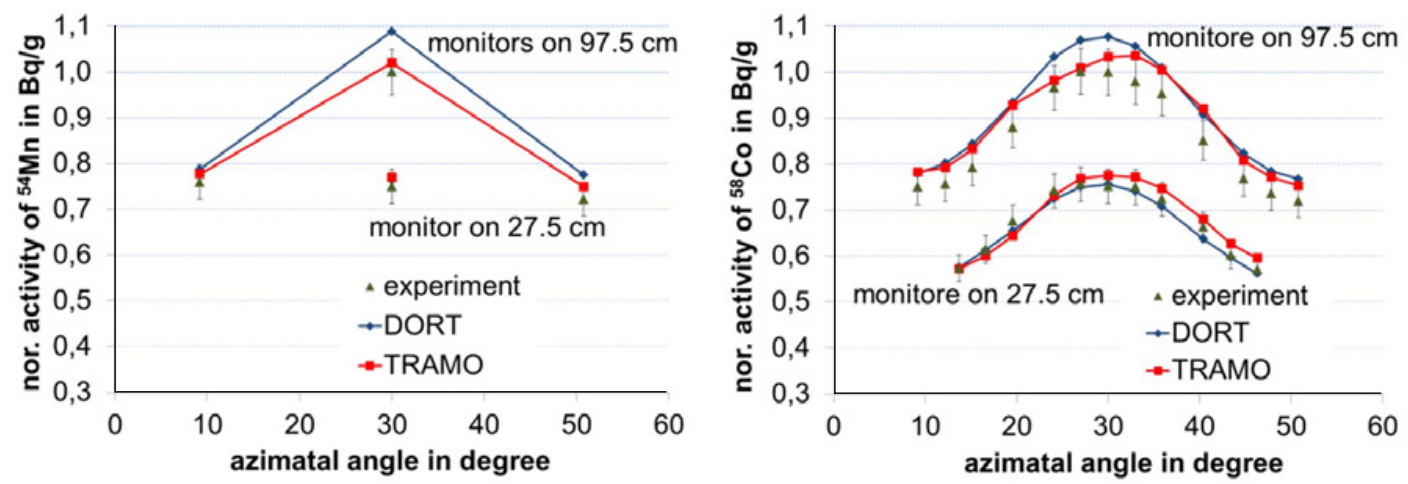

Figure 4. Normalized activities of the monitors in the two horizontal planes on $27.5 \mathrm{~cm}$ und $97.5 \mathrm{~cm}$.
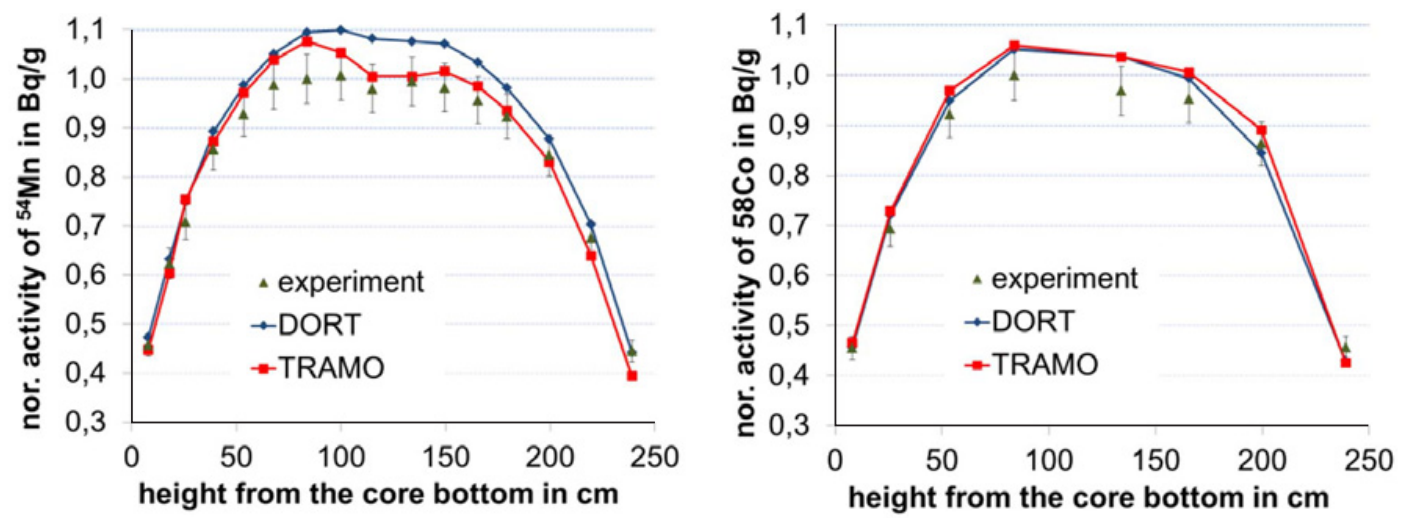

Figure 5. Normalized activities of the monitors the azimuthal angle of $30^{\circ}$.

maximum azimuthal flux at $30^{\circ}$, in the altitude range between $7.9 \mathrm{~cm}$ and $239 \mathrm{~cm}$. Sixteen monitors were installed on this line. Monitor materials ${ }^{58} \mathrm{Ni}$ and ${ }^{54} \mathrm{Fe}$ were mainly used. The (n,p) reaction is analysed for the determination of the neutron fluences. Other detector materials were used at exclusive positions. The exact positions of the various monitors are shown in the tables of the following Sect. 3.2.

\subsection{Comparisons}

On the two horizontal monitor planes, ${ }^{58} \mathrm{Ni}$ monitors were installed at all positions, but only four ${ }^{54} \mathrm{Fe}$ monitors. In contrast all positions of the vertical monitors were loaded with ${ }^{54} \mathrm{Fe}$ monitors and only eight ${ }^{58} \mathrm{Ni}$ monitors. Additional monitors were also on the heights of $25.7 \mathrm{~cm}, 100 \mathrm{~cm}$ and $115 \mathrm{~cm}$. For comparison, the activities were calculated at the end of cycle. Determination of the activities is based on the reaction rates of the monitors. The needed reaction cross sections were taken from the data library IRDF-2002 [9]. Figure 4 shows the normalized activities of the monitors in the two planes and Fig. 5 shows the monitors along the vertical line. The values were normalized for the horizontal planes on the experimental activity of the monitor at $30.0^{\circ}$ and $97.5 \mathrm{~cm}$ and for the vertical line on the experimental activity of the monitor at $83.7 \mathrm{~cm}$. Tables 1,2 and 3 show the corresponding calculation/experiment ratios $(\mathrm{C} / \mathrm{E})$. 
Table 1. C/E- and C/C ratios for the activities of the monitors on the $97.5 \mathrm{~cm}$ plane.

\begin{tabular}{|c|c|c|c|c|c|c|}
\hline \multirow{4}{*}{ Angle } & \multicolumn{4}{|c|}{ C/E } & \multicolumn{2}{c|}{ CORT $_{\text {DOR }}$} \\
\cline { 2 - 5 } & \multicolumn{2}{|c|}{ DORT } & \multicolumn{2}{c|}{ TRAMO } & \multicolumn{2}{c}{ CRAMO $_{\text {TRAMO }}$} \\
\cline { 2 - 5 } & ${ }^{\mathbf{5 4}} \mathbf{F e}$ & ${ }^{\mathbf{5 8}} \mathbf{N i}$ & ${ }^{\mathbf{5 4}} \mathbf{F e}$ & ${ }^{\mathbf{5 8}} \mathbf{N i}$ & ${ }^{\mathbf{5 4}} \mathbf{F e}$ & ${ }^{\mathbf{5 8}} \mathbf{N i}$ \\
\hline $\mathbf{9 . 2}$ & 1.04 & 1.04 & 1.02 & 1.04 & 1.01 & 1.00 \\
\hline $\mathbf{1 2 . 2}$ & & 1.06 & & 1.05 & & 1.01 \\
\hline $\mathbf{1 5 . 2}$ & & 1.07 & & 1.05 & & 1.01 \\
\hline $\mathbf{1 9 . 6}$ & & 1.06 & & 1.06 & & 1.01 \\
\hline $\mathbf{2 4 . 1}$ & & 1.07 & & 1.02 & & 1.05 \\
\hline $\mathbf{2 7}$ & & 1.07 & & 1.01 & & 1.06 \\
\hline $\mathbf{3 0}$ & 1.09 & 1.08 & 1.02 & 1.03 & 1.07 & 1.04 \\
\hline $\mathbf{3 3}$ & & 1.08 & & 1.06 & & 1.02 \\
\hline $\mathbf{3 5 . 9}$ & & 1.06 & & 1.05 & & 1.00 \\
\hline $\mathbf{4 0 . 4}$ & & 1.07 & & 1.08 & & 0.99 \\
\hline $\mathbf{4 4 . 8}$ & & 1.07 & & 1.05 & & 1.02 \\
\hline $\mathbf{4 7 . 8}$ & & 1.07 & & 1.05 & & 1.02 \\
\hline $\mathbf{5 0 . 8}$ & 1.07 & 1.07 & 1.04 & 1.05 & 1.03 & 1.02 \\
\hline
\end{tabular}

Table 2. C/E- and C/C ratios for the activities of the monitors on the $27.5 \mathrm{~cm}$ plane.

\begin{tabular}{|c|c|c|c|c|c|c|}
\hline \multirow{3}{*}{ Angle } & \multicolumn{4}{|c|}{$\mathrm{C} / \mathrm{E}$} & \multirow{2}{*}{\multicolumn{2}{|c|}{$\begin{array}{l}\mathbf{C}_{\text {DORT }} / \\
\mathbf{C}_{\text {TRAMO }}\end{array}$}} \\
\hline & \multicolumn{2}{|c|}{ DORT } & \multicolumn{2}{|c|}{ TRAMO } & & \\
\hline & ${ }^{54} \mathrm{Fe}$ & ${ }^{58} \mathrm{Ni}$ & ${ }^{54} \mathrm{Fe}$ & ${ }^{58} \mathrm{Ni}$ & ${ }^{54} \mathrm{Fe}$ & ${ }^{58} \mathrm{Ni}$ \\
\hline 13.7 & & 1.00 & & 1.00 & & 1.01 \\
\hline 16.6 & & 1.00 & & 0.98 & & 1.02 \\
\hline 19.6 & & 0.97 & & 0.95 & & 1.02 \\
\hline 24.1 & & 0.97 & & 0.99 & & 0.99 \\
\hline 27 & & 0.99 & & 1.02 & & 0.98 \\
\hline 30 & 1.02 & 1.01 & 1.03 & 1.03 & 0.99 & 0.98 \\
\hline 33 & & 0.99 & & 1.03 & & 0.96 \\
\hline 35.9 & & 0.98 & & 1.03 & & 0.95 \\
\hline 40.4 & & 0.96 & & 1.03 & & 0.94 \\
\hline 43.4 & & 0.99 & & 1.04 & & 0.95 \\
\hline 46.3 & & 0.98 & & 1.04 & & 0.94 \\
\hline
\end{tabular}

The average of the C/E ratios with TRAMO on the height of $27.5 \mathrm{~cm}$ for the ${ }^{58} \mathrm{Ni}$ monitors is 1.01 and on the height of $97.5 \mathrm{~cm} 1.05$. The corresponding results from DORT are 0.99 and 1.07 . These good results demonstrate the quality of validation of the calculation methods. However, at the level of 97.5, the calculated values are somewhat too big for both TRAMO and DORT. It may be assumed the small deviations are generated by errors in the input data or in the experiments.

Similar differences show in the $\mathrm{C} / \mathrm{E}$ values of the vertical monitors. In contrast to the horizontal monitors, the TRAMO results are slightly higher than those of DORT, as expected.

In the TRAMO calculation, a reduction in the activity at the ${ }^{54} \mathrm{Fe}$ monitor at $115 \mathrm{~cm}$ above the core bottom is evident. This reduction can also be seen in the experimental value. The shielding effect of a baffle rib was found to be a cause of the reduction. The monitor position is directly at the level of a baffle rib. The activation reactions have a high threshold energy and therefore can be initiated mainly by direct fission neutrons. Despite the great distance, the influence of the larger absorption of the steel compared to water is therefore present. In order to extract the effect of the ribs, comparison calculations are carried out without the baffle ribs. In these calculations, there was no such reduction.

In addition, the influence of the channel, including the SS containers, was investigated on the monitor results. As a basis for comparison, calculations are carried out where the channel was removed. It shows that a significant influence exists only in the energy region above $3 \mathrm{MeV}$. 
$15^{\text {th }}$ ISRD

Table 3. C/E- and $\mathrm{C} / \mathrm{C}$ ratios for the activities of the monitors on the azimuthal angle of $30^{\circ}$.

\begin{tabular}{|c|c|c|c|c|c|c|}
\hline \multirow{3}{*}{ Height } & \multicolumn{4}{|c|}{$\begin{array}{c}\text { Calculation /experiment } \\
\text { C/E }\end{array}$} & \multirow{2}{*}{\multicolumn{2}{|c|}{$\begin{array}{l}\mathbf{C}_{\text {DORT }} / \\
\mathbf{C}_{\text {TRAMO }} \\
\end{array}$}} \\
\hline & \multicolumn{2}{|c|}{ DORT } & \multicolumn{2}{|c|}{ TRAMO } & & \\
\hline & ${ }^{54} \mathrm{Fe}$ & ${ }^{58} \mathrm{Ni}$ & ${ }^{54} \mathrm{Fe}$ & ${ }^{58} \mathbf{N i}$ & ${ }^{54} \mathrm{Fe}$ & ${ }^{58} \mathrm{Ni}$ \\
\hline 7.9 & 1.03 & 1.00 & 0.98 & 1.02 & 1.06 & 0.98 \\
\hline 17.9 & 1.01 & & 0.97 & & 1.05 & \\
\hline 25.7 & 1.06 & 1.04 & 1.06 & 1.05 & 0.99 & 0.99 \\
\hline 39 & 1.04 & & 1.02 & & 1.02 & \\
\hline 53.5 & 1.06 & 1.03 & 1.05 & 1.05 & 1.02 & 0.98 \\
\hline 67.9 & 1.06 & & 1.05 & & 1.01 & \\
\hline 83.7 & 1.09 & 1.05 & 1.08 & 1.06 & 1.02 & 0.99 \\
\hline 100 & 1.09 & & 1.05 & & 1.04 & \\
\hline 115 & 1.10 & & 1.03 & & 1.08 & \\
\hline 134 & 1.08 & 1.07 & 1.01 & 1.07 & 1.07 & 1.00 \\
\hline 149.5 & 1.09 & & 1.03 & & 1.06 & \\
\hline 165.5 & 1.08 & 1.04 & 1.03 & 1.06 & 1.05 & 0.99 \\
\hline 179.3 & 1.06 & & 1.01 & & 1.05 & \\
\hline 199.5 & 1.04 & 0.98 & 0.98 & 1.03 & 1.06 & 0.95 \\
\hline 219.5 & 1.04 & & 0.95 & & 1.10 & \\
\hline 239 & 0.99 & 0.94 & 0.89 & 0.93 & 1.12 & 1.01 \\
\hline
\end{tabular}

Table 4. Average flux $>0.5 \mathrm{MeV}$ surveillance specimen.

\begin{tabular}{|l|l|}
\hline $\begin{array}{l}\text { Height from } \\
\text { core bottom } \\
\text { in cm }\end{array}$ & Average Flux \\
\hline $\mathbf{2 5}$ & $1.75 \mathrm{E}+12$ \\
\hline $\mathbf{5 0}$ & $2.29 \mathrm{E}+12$ \\
\hline $\mathbf{7 5}$ & $2.44 \mathrm{E}+12$ \\
\hline $\mathbf{1 0 0}$ & $2.41 \mathrm{E}+12$ \\
\hline $\mathbf{1 2 5}$ & $2.35 \mathrm{E}+12$ \\
\hline $\mathbf{1 5 0}$ & $2.27 \mathrm{E}+12$ \\
\hline $\mathbf{1 7 5}$ & $2.19 \mathrm{E}+12$ \\
\hline $\mathbf{2 0 0}$ & $1.96 \mathrm{E}+12$ \\
\hline $\mathbf{2 2 5}$ & $1.35 \mathrm{E}+12$ \\
\hline
\end{tabular}

\section{Surveillance Specimens}

\subsection{Fluence Calculations}

Besides the calculation of the neutron fluences in the SS, a focus lay on the determination of their uncertainties. The uncertainties are generated on the one side by the displacement of containers within the channel and on the other hand by their alignment with the reactor core. The containers were accurately represented in the TRAMO calculations in the radial direction (see Fig. 2). In contrast, DORT divides the geometry based on the fixed calculation grid so that no direct comparison of fluence values is possible. Therefore, the values compared are geometrical neighbours, and good agreements were obtained. Differences in the fluence $\mathrm{E}>0.5 \mathrm{MeV}$ max. $10 \%$ were determined, which in part results from the local differences of values. As an example, Table 4 shows the average neutron flux $>0.5 \mathrm{MeV}$ as result of the TRAMO calculation in the SS at different height positions.

Approximately $2.45 \times 10^{12}$ neutrons $/ \mathrm{cm}^{2}$ were reached for all SS in the altitude range from 75 to $150 \mathrm{~cm}$. The differences are less than $10 \%$. With average cycle times, the "end of life" fluence would be achieved in the SS after only two years. Although the "end of life" fluence depends on the material composition of the RPV steel, it can be roughly assumed at $1.0 \times 10^{20}$ neutrons $/ \mathrm{cm}^{2}$. 


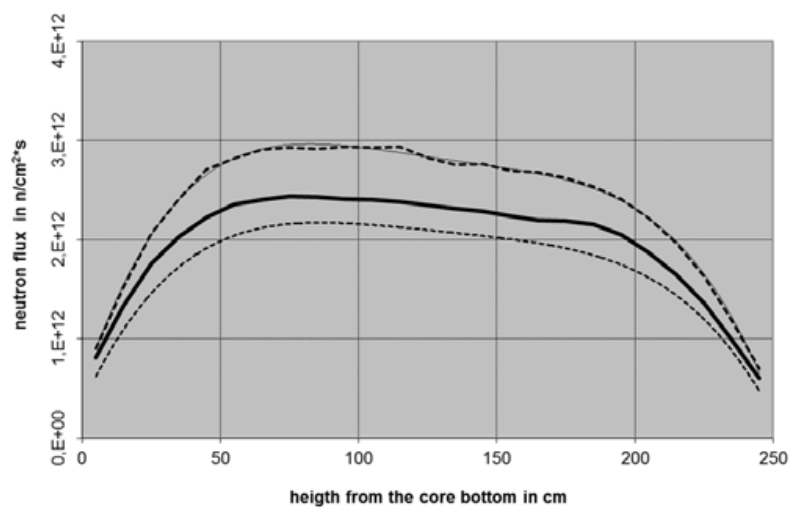

Figure 6. The average neutron flux with the possible fluctuation.

The existing model could be used to account for the uncertainties caused by the orientation of the container to the reactor core. Because of the symmetrical arrangement of the channels to the reactor core, the extremes could be determined in a calculation. New models were created to establish the uncertainties caused by the displacement of containers within the channel. The differences in the neutron flux were calculated to be $30 \%$. Figure 6 shows the average neutron flux with the possible fluctuation. The main part, with up to $20 \%$, is due to not knowing the exact orientation of the specimen containers to the reactor core. It can be assumed that the orientation of the containers does not vary during the irradiation, and thus the possible difference between the calculated and the real flux is constant. In contrast, the position of containers can be changed within the channel, so here the maximum error differences are probable. For the sake of completeness, it should be mentioned that the mean statistical errors in the calculated integral values were estimated at smaller than $1 \%$. Errors based on the uncertainties of cross-sectional data, material composition and other input data were not considered here.

\subsection{Heating}

The main energy for a possible heating of the SS is supplied by gamma radiation. Coupled neutron/gamma calculations for the gamma of the neutron reactions and separate calculations for the fission gammas were carried out for the determination of the gamma fluences of the SS. The energy deposition was determined by means of MCNP and a model of the container. An energy input of $0.057 \mathrm{~J} / \mathrm{s}$ per g material was found for the gamma flux and 0.00052 for the neutron flux.

The stationary temperature distribution in the SS was calculated based on simplified geometries in order to make the problem amenable to analytic treatment. Two cases were defined which correspond to the upper and lower limits of the expected temperature range. The lower limit is established by a hollow cylinder with a concentrically embedded SS capsule that is cooled around its entire circumference, and the upper limit by approximating the SS as an additional heated shell around the core barrel with onedimensional heat conduction in the radial direction.

The heat conduction equation in cylinder coordinates was solved analytically:

$$
\frac{1}{r} \frac{d}{d r}\left(r \frac{d T}{d r}\right)+\frac{q}{r}=0
$$

where $q$ is the volumetric heat source in the capsule. With the given specific energy deposition from the MCNP calculation and assuming steel as the heated material, $q$ amounts to $0.48 \mathrm{~kW} / \mathrm{m}^{3}$. 


\section{$15^{\text {th }}$ ISRD}

The heat transfer coefficient $\alpha$ at the outer channel surface depends on the flow characteristics of the coolant. Assuming standard operation parameters of $41500 \mathrm{~m}^{3} / \mathrm{h}$ coolant mass flow and $267{ }^{\circ} \mathrm{C}$ coolant temperature in the down comer, the heat transfer coefficient was estimated to be $24 \mathrm{~kW} / \mathrm{m}^{2}$. Based on these conditions the temperature profile in the SS capsule was calculated. In the capsule centre, temperatures of $270.5^{\circ} \mathrm{C}$ were found for the lower limiting case and $286^{\circ} \mathrm{C}$ for the conservative approach. From these values it can be concluded that healing effects due to excessive heating of the RPV steel can be excluded.

\section{Conclusion}

On the basis of neutron transport, calculations with important integral fluences $\mathrm{E}>0.5$ and $1.0 \mathrm{MeV}$ for material embrittlement have been determined in the SS of a VVER-440/213. The calculations are carried out with both the TRAMO and DORT codes.

The calculations were validated on activation monitors, which were irradiated at the RPV outer surface of Kola NPP's Unit 3. Activation monitors with the reactions ${ }^{54} \mathrm{Fe}(\mathrm{n}, \mathrm{p}){ }^{54} \mathrm{Mn}$ and ${ }^{58} \mathrm{Ni}(\mathrm{n}, \mathrm{p}){ }^{58} \mathrm{Co}$ were mainly used. The C/E ratios are between 0.89 and 1:08 for TRAMO and 0.94 and 1:10 for DORT, but the most are 1:00 to 1:05. It should be emphasized that an influence of the baffle ribs could be detected on the monitor activities.

With both programs, an average flow of about $2.45 \times 10^{12}$ neutrons $/ \mathrm{cm}^{2} \mathrm{~s}$ was calculated in the SS for integral value $\mathrm{E}>0.5 \mathrm{MeV}$ in the region of the core. This value can vary depending on the orientation of the sample to the reactor core by up to $20 \%$. In addition, more deviations up to $10 \%$ may occur due to the change in position of the irradiation container in the channel. The "end of life" fluence for RPV steel would be achieved at standard cycle times in the SS after 2 years.

Annealing processes may have taken place due to high temperatures in the SS, therefore the possible heating was determined. Based on the gamma fluxes, the average energy input was calculated. Using a simple thermohydraulic model, an increase in temperature of about $20 \mathrm{~K}$ was calculated in the SS. Assuming realistic conditions, the heating is reduced to less than $5 \mathrm{~K}$, which approximately agrees with the corresponding measurements.

This work was supported in part by the bilateral scientific-technical cooperation agreement between Germany and Russia through the project of the Ministry of Economics and Technology of Germany.

\section{References}

[1] H.-U. Barz and J. Konheiser, FZR Bericht-245, Rossendorf (1998)

[2] W. Rhoades and R. Childs, CCC-543, RSIC, ORNL, TN (1991)

[3] K. Torronen and et al., IAEA Specialists Meeting, Vienna (1984)

[4] M. Chadwick and et al., Nuclear Data Sheets, Bd. Issue 12, Nr. Volume 112, pp. 2887-2996 (2011)

[5] R. W. Roussin and et al., Oak Ridge National Lab, Oak Ridge, Tennessee, 1983

[6] L. Abagyan, N. O. Bazazyants, M. N. Nikolaev and A. M. Tsibulia, Group Constants for Reactor and Shielding Calculations, Moscow, Energoizdat (1981)

[7] S. B. Ludwig and J. P. Renier, ORNL/TM-11018 (1989)

[8] J. E. White and et al., Production and Testing of the Revised VITAMIN-B6 Fine-Group and the BUGLE-96 Broad-Group Neutron/Photon Cross-Section Libraries Derived from ENDF/B-VI.3 Nuclear Data," ORNL-6795, R1, NUREG/CR-6214, Revision 1 (1995)

[9] O. Bersillon et al., A. International Reactor Dosimetry File 2002 (IRDF-2002), International Atomic Energy Agency Vienna 2006 